\title{
Enhanced Catalytic Performance of Strontium-Doped Lanthanum Manganites by the Presence of Molybdenum Oxides for Electro-Reduction of Hydrogen Peroxide
}

\author{
Ludmila G. O. Xavier, ${ }^{a}$ Thérèse C. Ebambi, ${ }^{a}$ Renata Diniz, ${ }^{a}$ Vanessa F. C. Lins, ${ }^{b}$ \\ Luciano A. Montoro ${ }^{a}$ and Tulio Matencio ${ }^{\circledR} * a$ \\ ${ }^{a}$ Departamento de Química, Universidade Federal de Minas Gerais, \\ 30161-970 Belo Horizonte-MG, Brazil \\ ${ }^{b}$ Departamento de Engenharia Química, Escola de Engenharia, \\ Universidade Federal de Minas Gerais, 30161-970 Belo Horizonte-MG, Brazil
}

\begin{abstract}
In this work, two catalysts, lanthanum manganite strontium-doped perovskite without (LSM) and with (LSMMO) mixed molybdenum oxides, were synthesized by the sol-gel route and deposited by immersion in carbon cloth substrates. Their performance as cathodes in the hydrogen peroxide reduction reaction (HPRR) and oxygen reduction reaction (ORR) was investigated through cyclic voltammetry and electrochemical impedance spectroscopy, the electrocatalytic efficiency of these electrodes in the HPRR was analyzed in $\mathrm{KOH}$ and $\mathrm{H}_{2} \mathrm{O}_{2}$ medium at $298 \mathrm{~K}$. The performance of the cathodes, in a single compartment, using a nickel plate as an anode was also investigated. The results showed that for the reduction reactions, electrodes developed with LSMMO have more significant catalytic activity than LSM after polarization, resulting in 32\% higher current densities, lower electrical resistance after polarization, and a $21 \%$ increase in power density.
\end{abstract}

Keywords: electrocatalyst, hydrogen peroxide electro-reduction, molybdenum oxides, perovskite phase

\section{Introduction}

Fuel cells are devices that convert chemical energy into electricity. The electrochemical reactions that occur during their operation present high energy efficiency, low environmental and noise pollutions and can be used on mobile and portable devices. ${ }^{1,2}$ Fuel cells are increasingly being studied due to the growing demand for cleaner, renewable and more affordable decentralized energy sources. ${ }^{3,4}$

Direct liquid fuel cells, DLFCs, are an interesting power source for the automotive industry because of their higher energy densities than lithium-ion batteries. ${ }^{4,5}$ Different liquids have been proposed as fuel to develop such fuel cells, for example, methanol (DMFCs), ${ }^{6}$ ethylene glycol (DEGFCs), ${ }^{7}$ glycerol (DGFCs) ${ }^{8}$ formic acid (DFAFCs) ${ }^{9}$ and hydrazine acid (DHFCs) ${ }^{10}$ among others. ${ }^{4}$ However, for applications in thin air-free systems, the use of oxygen is not feasible due to the difficulty of storage. ${ }^{11}$

*e-mail: tmatencio@ufmg.br

Editor handled this article: Rodrigo A. A. Muñoz (Associated)
From this perspective, hydrogen peroxide is a promising alternative in DLFCs. The high solubility of $\mathrm{H}_{2} \mathrm{O}_{2}$ in water promotes greater safety for handling and transportation. ${ }^{11-13}$ Furthermore, studies have shown that the peroxide reduction reaction (HPRR) (equation 1), presents faster reaction speed than the oxygen reduction reaction (ORR) (equation 2), resulting in lower activation losses. ${ }^{14-18}$ Besides, hydrogen peroxide can also be electrooxidized to $\mathrm{O}_{2}$ (equation 3), allowing its use both as a fuel and an oxidant. ${ }^{4}$ This particularity paves the way for developing direct hydrogen peroxide cells. ${ }^{11}$

$$
\begin{aligned}
& \mathrm{HO}_{2}^{-}+\mathrm{H}_{2} \mathrm{O}+2 \mathrm{e}^{-} \rightleftarrows 3 \mathrm{OH}^{-} \\
& \mathrm{O}_{2}+2 \mathrm{H}_{2} \mathrm{O}+4 \mathrm{e}^{-} \rightleftarrows 4 \mathrm{OH}^{-} \\
& \mathrm{HO}_{2}^{-}+\mathrm{OH}^{-} \rightleftarrows \mathrm{O}_{2}+\mathrm{H}_{2} \mathrm{O}+2 \mathrm{e}^{-} \\
& \mathrm{H}_{2} \mathrm{O}_{2}+\mathrm{OH}^{-} \rightleftarrows \mathrm{H}_{2} \mathrm{O}+\mathrm{HO}_{2}^{-} \\
& 2 \mathrm{HO}_{2}^{-} \rightleftarrows \mathrm{O}_{2}+2 \mathrm{OH}^{-}
\end{aligned}
$$

Although $\mathrm{H}_{2} \mathrm{O}_{2}$ presents the advantages listed above, its utilization is also challenging. In DLFCs, part of the $\mathrm{H}_{2} \mathrm{O}_{2}$ species is adsorbed and electrocatalytically reduced onto the cathode surface while another part of the $\mathrm{H}_{2} \mathrm{O}_{2}$ species in solution undergoes a spontaneous decomposition 
producing $\mathrm{O}_{2}$ (equations 4 and 5). If the decomposition reaction of $\mathrm{H}_{2} \mathrm{O}_{2}$ is favored, the gas produced induces the desorption of the hydrogen peroxide onto the electrode and, consequently, decreases the cell power density. Besides, the further adsorption of $\mathrm{O}_{2}$ onto the electrocatalyst surface reduces the active surface area. ${ }^{12}$ Therefore, the solution proposed in this research is to develop electrocatalysts that promote the catalysis of both species.

Perovskites, especially strontium-doped lanthanum manganite ( $\mathrm{LSM}$ : $\mathrm{La}_{1-\mathrm{x}} \mathrm{Sr}_{\mathrm{x}} \mathrm{MnO}_{3-\mathrm{d}}$ ), have received considerable interest as promising cathodic materials due to their remarkable catalytic performance for reduction, abundance, low cost, non-toxicity and stable alkaline medium. ${ }^{19,20}$

The catalytic activity of these oxides is associated with the species $\mathrm{Mn}^{3+} / \mathrm{Mn}^{4+}$ and the proportion between these two species influences the redox processes by producing oxygen vacancies. ${ }^{16}$ These systems have proved to perform the hydrogen peroxide reduction reaction (HPRR) efficiently. ${ }^{11,12,16-20}$ Lanthanum manganites (LSM) are presented as reliable materials with good electrocatalytic activity. ${ }^{21}$

Among non-noble metal materials, various molybdenum materials are known for their high catalytic activity and selectivity in redox reactions. ${ }^{22-24}$ The $\mathrm{MoO}_{2}$ has an electronic conductivity associated with a relatively high density of valence band states, comparable to many metals. ${ }^{25}$ In molybdenum perovskites, such as $\mathrm{SrMoO}_{3}$, a notable conductivity has also been reported. Despite mixed oxidation states of $\mathrm{Mo}\left(\mathrm{Mo}^{2+}\right.$ and $\left.\mathrm{Mo}^{5+}\right)$, an oxygen vacancy is not promoted in these structures; therefore, oxygen diffusion is hindered. ${ }^{22,25}$

However, joining perovskites and molybdenum, mixed oxides can generate new electrode materials with high conductivity and improve electrocatalytic performance. This work aims firstly to produce strontium-doped lanthanum manganite mixed with molybdenum oxides by the Pechinni route, secondly to have electrodes with the produced oxides supported on carbon cloth, thirdly to characterize their microstructures and finally to evaluate the catalytic activity by voltammetry and electrochemical impedance spectroscopy for application as HPRR and ORR electrocatalysts.

\section{Experimental}

\section{Materials and electrodes}

Mixed oxides materials, LSM $\left(\mathrm{La}_{1-\mathrm{x}} \mathrm{Sr}_{\mathrm{x}} \mathrm{MnO}_{3-\mathrm{d}}\right)$ and LSMMO $\left(\mathrm{La}_{1-x} \mathrm{Sr}_{x} \mathrm{MnO}_{3-\mathrm{d}}\right.$ and $\left.\mathrm{La} / \mathrm{SrMoO}_{y}\right)$, were synthesized via the citric acid sol-gel precursor method according to previous reports. ${ }^{26,27}$ To synthesized LSM, the precursor citric acid $(3.5 \mathrm{~mol})$ (> $99.0 \mathrm{wt} . \%$ Synth, São Paulo, Brazil) was mixed with $\mathrm{La}\left(\mathrm{NO}_{3}\right)_{3} \cdot 6 \mathrm{H}_{2} \mathrm{O}$ (0.8 mol) (> 99.9 wt.\% J. T. Baker, New Jersey, USA), $\mathrm{Sr}\left(\mathrm{NO}_{3}\right)_{2}$ (0.4 mol) (> 99.9 wt.\% Dinâmica, São Paulo, Brazil), $\mathrm{Mn}\left(\mathrm{CH}_{3} \mathrm{COO}\right)_{2}(1.0 \mathrm{~mol})$ (> 99.9 wt.\% Vetec, Rio de Janeiro, Brazil), and polyethylene glycol (66.7\% $\mathrm{m} / \mathrm{m}$ citric acid) (> 95.0 wt.\% Neon, São Paulo, Brazil) obtaining a resin-like solution. To prepare the LSMMO, $\left(\mathrm{NH}_{4}\right)_{6} \mathrm{Mo}_{7} \mathrm{O}_{24}(>99.9 \mathrm{wt}$ \% Fmaia, Belo Horizonte, Brazil) was added to the resin solution in the molar proportion of $80 \%$ manganese and $20 \%$ molybdenum. The reagents were previously dissolved in deionized water.

The two resin solutions obtained during the first step were heated at $350{ }^{\circ} \mathrm{C}$ for two hours and black powders (LSM and LSMMO) were formed. Subsequently, the powders were calcined at $900{ }^{\circ} \mathrm{C}$ for $24 \mathrm{~h}\left(0.6{ }^{\circ} \mathrm{C} \mathrm{min}{ }^{-1}\right.$ heating rate) under the air atmosphere. Fine powders with particles below $90 \mu \mathrm{m}$ were then used for electrode preparation.

To obtain the electrodes suspensions, LSM and LSMMO fine powders were individually dispersed in polymethyl pyrrolidone (99.0 wt.\% Merck, Darmstadt, Germany) and acetone (99.0 wt.\% Aldrich, Missouri, USA). To that dispersion was added carbon black $(20 \% \mathrm{~m} / \mathrm{m}$ Carbon Black Thai Public Co., Ltd, Bangkok, Thailand) and polyvinylidene fluoride (PVDF, 10\% m/m Solef 1012 Solvay, São Paulo, Brazil) before submitted to ultrasound for $30 \mathrm{~min}$.

The Carbon Cloth CC4 Plain (Fuel Cell Earth, Massachusetts, USA) of $1.0 \mathrm{~cm}^{2}$ area was used as the electrode support. The LSM and LSMMO suspensions were deposited onto the carbon cloth using the dip-coating method, with an ascent rate of $5.0( \pm 0.02) \mathrm{cm} \mathrm{min}^{-1}$, obtaining the mass of 13-15 mg of active material on the electrode. After deposition, the electrodes were dried at $70{ }^{\circ} \mathrm{C}$ for $2 \mathrm{~h}$.

Powders and electrodes of mixed oxides of molybdenum with lanthanum (LaMo) or with strontium (SrMo), without perovskite, were also prepared and described in the Supplementary Information (SI) section.

\section{Microstructural characterizations}

Microstructural imaging and analysis were performed by scanning electron microscopy (SEM, Quanta FEG 3D FEI, Oregon, USA) coupled with an X-ray spectrometer EDS (energy-dispersive X-ray spectroscopy). The structure of LSM and LSMMO catalysts was characterized by the powder X-ray diffraction (XRD, Shimadzu XRD-7000, Tokyo, Japan), diffractometer equipped with $\mathrm{Cu} \mathrm{K \alpha}$ 
radiation at room temperature. The data collection was performed between $20^{\circ}$ and $70^{\circ}$ in $2 \theta$ with a step size of $0.02^{\circ}$ and a scan speed of $0.28^{\circ} \mathrm{min}^{-1}$. Surface area and pores characterization of LSM and LSMMO powders were obtained from Brunauer-Emmett-Teller (BET) analysis (Quantachrome ASiQwin, Florida, USA), using nitrogen, pretreated with 50 adsorption-desorption cycles, $200{ }^{\circ} \mathrm{C}$ final outgas temperature. The roughness factor of the LSM and LSMMO electrodes supported on the carbon cloth was calculated from the topographic analysis of the T4000 profilometer (Homemelwerke, VS-Schwenningen Germany) results. With the probe TKL 100/17 (tip of $90^{\circ}$ of inclination and $5 \mu \mathrm{m}$ of radius), using the fixed support model FHZ, 10 measurements were made for each specimen with $50 \mu \mathrm{m}$ pitch in a swept area of $2.5 \times 4.5 \mathrm{~mm}$. The measurement speed used was $0.01 \mathrm{~mm} \mathrm{~s}^{-1}$. The cut-off filters were compatible with the minimum transverse length (Lt), six times greater than the cut-off length. The statistical parameters of surface roughness (roughness and undulation) were obtained using the Turbo Roughness software and the Hommelmap Expert 3.0 software.

\section{Electrochemical measurements}

The electrocatalytic activity of the LSM and LSMMO electrodes supported on carbon cloth was measured in a standard three-electrode system using the LSM or LSMMO catalyst as the working electrode, $\mathrm{Ag} / \mathrm{AgCl} /$ saturated $\mathrm{KCl}$ as the reference electrode and $\mathrm{Pt}$ as the counter electrode. KOH (> 85.0 wt.\% Química Moderna, São Paulo, Brazil) solutions $\left(0.40 \mathrm{~mol} \mathrm{~L}^{-1}\right)$ with and without hydrogen peroxide (30.0-32.0 wt.\% Química Moderna, São Paulo, Brazil) (0.10, $0.09,0.08$ and $0.07 \mathrm{~mol} \mathrm{~L}^{-1}$ ) were used as an electrolyte, and the $\mathrm{N}_{2(\mathrm{~g})}$ was bubbled in the solutions before electrochemical measurements. The hydrogen peroxide reduction reaction kinetics was studied by cyclic voltammetry.

The evaluation of a complete direct $\mathrm{H}_{2} \mathrm{O}_{2} / \mathrm{H}_{2} \mathrm{O}_{2}$ cell in a single compartment was performed on the two electrode system using LSM and LSMMO electrodes as cathodes and a $1.00 \mathrm{~cm}^{2}$ area nickel plate as the anode in an electrolyte consisting of $0.10 \mathrm{M} \mathrm{H}_{2} \mathrm{O}_{2}$ and $0.40 \mathrm{~mol} \mathrm{~L}^{-1} \mathrm{KOH}$ and the $\mathrm{N}_{2(\mathrm{~g})}$ bubbled in the solutions before electrochemical measurements. Electrochemical impedance spectroscopy (EIS) measurements were taken before and after the electrodes were polarized in $-0.85 \mathrm{~V}$ for $300 \mathrm{~s}$ in $0.4 \mathrm{~mol} \mathrm{~L}^{-1}$ $\mathrm{KOH}$ electrolyte. The polarization effect was studied in the three-electrode system, with $\mathrm{Ag} / \mathrm{AgCl}$ as the reference electrode. The electrochemical behavior was also evaluated by electrochemical impedance spectroscopy (EIS), with a frequency range of $0.1 \mathrm{~Hz}-50 \mathrm{kHz}$ and an amplitude of $10 \mathrm{mV}$ for the input sine wave signal. The impedance and electrochemical measurements were performed using a PGSTAT AUTOLAB 302 with an FRA impedance module and FRA and GPES software. The ZView ${ }^{\circledR}$ software version $2.8 \mathrm{~d}$ was used to simulate the parameters of the equivalent circuits.

\section{Results and Discussion}

\section{Microstructures of coated electrodes}

The powder XRD patterns of LSM and LSMMO are displayed in Figure 1. The Rietveld refinement qualitative analysis indicates the presence of two phases in the LSM sample: $\mathrm{La}_{0.5} \mathrm{Sr}_{0.5} \mathrm{MnO}_{3}$ (trigonal space group $\mathrm{R}-3 \mathrm{c}$ ) and $\mathrm{La}_{2} \mathrm{O}_{3}$ (cubic space group Ia-3). ${ }^{28,29}$ The LSMMO is constituted by three crystallographic phases: $\mathrm{La}_{\mathrm{x}} \mathrm{Sr}_{1-\mathrm{x}} \mathrm{MnO}_{3}$ (trigonal space group $\mathrm{R}-3 \mathrm{c}$ ), $\mathrm{SrMoO}_{4}$ (tetragonal space group $\mathrm{I}_{1} / \mathrm{a}$ ) and $\mathrm{La}_{2} \mathrm{MoO}_{6}$ (tetragonal space group I-4c2). ${ }^{30,31}$ This analysis suggests that in the LSMMO sample, Mo was not present in the $\mathrm{La}_{0.5} \mathrm{Sr}_{0.5} \mathrm{MnO}_{3}$ phase as intended, but it is distributed in the phases $\mathrm{SrMoO}_{4}$ and $\mathrm{La}_{2} \mathrm{MoO}_{6}$. The quantitative analysis by Rietveld refinement was also performed in both samples (Figures S1-S2, Table S1, SI section). ${ }^{32}$ In LSM, the best refinement indicates that the mass percentual is 80.5(2) for $\mathrm{La}_{\mathrm{x}} \mathrm{Sr}_{1-\mathrm{x}} \mathrm{MnO}_{3}$ and 19.5(2) for $\mathrm{La}_{2} \mathrm{O}_{3}$, and the $\mathrm{x}$ value was optimized to $0.55(3)$. For LSMMO, the Rietveld analysis shows statistic parameters with less quality than LSM. The mass percentual for LSMMO after the best refinement were 54(1), 34(1) and 12(1), for $\mathrm{La}_{\mathrm{x}} \mathrm{Sr}_{1-\mathrm{x}} \mathrm{MnO}_{3}, \mathrm{SrMnO}_{4}$ and $\mathrm{La}_{2} \mathrm{MoO}_{6}$, respectively. The $\mathrm{x}$ value was optimized to $0.50(5)$ in this sample, equivalent to the $\mathrm{x}$ value obtained in the LSM sample. This result indicates that in both samples, the phase $\mathrm{La}_{\mathrm{x}} \mathrm{Sr}_{1-\mathrm{x}} \mathrm{MnO}_{3}$ is the same.

LSM and LSMMO diffraction patterns present peaks at $33^{\circ}$ and $47^{\circ}$ with high magnitude and can be ascribed respectively as 102 and 204 peaks, typical to ( $\mathrm{LaSr}) \mathrm{MnO} 3{ }^{33}$

The mixed oxides of molybdenum with strontium or lanthanum were synthesized via Pechinni methods and their powders were analyzed by XRD (Figure S1, SI section).

The catalytic activity of rare earth oxides is widely studied for speed-up reactions such as ORR and HPRR. ${ }^{27}$ However, individually, these oxides' activity generally has low efficiency. To promote better catalytic performance, the synergy between the properties of catalytically active materials and those of the earth oxides is fundamental. In the presence of $\mathrm{La}_{2} \mathrm{O}_{3}$ for the HPRR reaction, strontiumdoped lanthanum manganite was investigated in some studies. ${ }^{27,34}$ Both works reported that the performance of LSM is more significant than the $\mathrm{La}_{2} \mathrm{O}_{3}$, which is mainly due to the property of the perovskite to promote a better 
diffusion of active species in the structure. However, its ionic conduction can promote a better response in the system as a whole. ${ }^{35}$

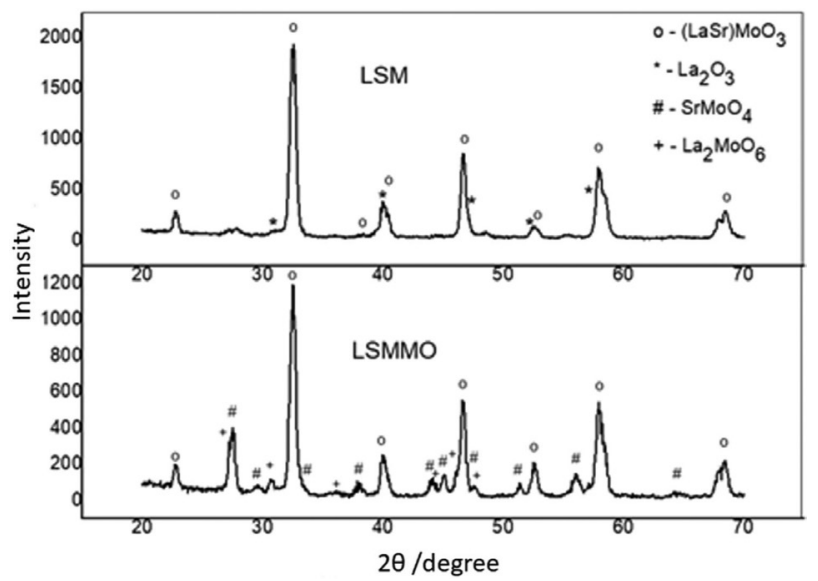

Figure 1. XRD patterns of electrode powders LSM and LSMMO.

BET characterization indicated a surface area of LSMMO powder $15 \%$ smaller than LSM. The measured surface area for LSM and LSMMO was 4.3 and $3.7 \mathrm{~m}^{2} \mathrm{~g}^{-1}$, respectively. Fearn et al. ${ }^{36}$ and Jouannaux et al..$^{37}$ reported LSM surface areas between 3.9 and $4.3 \mathrm{~m}^{2} \mathrm{~g}^{-1}$. The values obtained in this work are, thus, in agreement with the surface area found in the literature for perovskites obtained via Pechini methods.

The surface roughness statistical parameters and the actual surface area of the LSM and LSMMO electrodes supported on carbon cloth were calculated using the $\mathrm{Sdr}$ parameter obtained by profilometer measurements. For statistical analysis of surface roughness parameters, the contact angles obtained in the states of Cassie-Baxter (3D) and Wenzel (2D) are related to horizontal and vertical characteristics of the surface topography. ${ }^{38,39}$ These angles are related to the hydrophilicity of the samples so that the $\theta_{\mathrm{s}}$ statistical contact angle between the fluid and the microstructure is given by equation $6 .^{38}$

The statistical parameters extracted from this analysis, $\mathrm{Sa}$, are associated with mean height difference for the surface, Sz, summation of peaks and valleys within the analyzed area and Sku, are associated with the geometry of the peaks and valleys and evaluates the degree of contact of the surface. Sdr is a parameter determined from the height and horizontal parameters of the surface. The relation $(1+\mathrm{Sdr})$ can be understood as the area of the additional surface in relation to the flat surface (equation 7) and is analogous to the roughness factor (R) (equation 8) for the Wenzel state. ${ }^{38,40}$

$\cos \theta_{s}=-1+f(1+\cos \theta)$ $\mathrm{f}=\frac{\text { actual solid and fluid contact area }}{\text { planar area }}$

$\mathrm{R}=\frac{\text { actual surface area }}{\text { planar area }}$

where $\theta$ is the contact angle in Wenzel state, and $f$ is the fraction of the solid-fluid contact area.

In this work, the planar surface area for both electrodes supported on the carbon cloth is $1.0 \mathrm{~cm}^{2}$. Table 1 displays the statistical parameters for assessing the roughness of the LSM and LSMMO electrodes.

Table 1. Statistics parameters for the roughness study of LSM and LSMMO electrodes supported on carbon cloth

\begin{tabular}{lcccc}
\hline $\begin{array}{l}\text { Electrode } \\
\begin{array}{l}\text { supported on } \\
\text { carbon cloth }\end{array}\end{array}$ & $\mathrm{Sa} / \mu \mathrm{m}$ & $\mathrm{Sz} / \mu \mathrm{m}$ & $\mathrm{Sku}$ & $\mathrm{Sdr} / \%$ \\
\hline $\mathrm{LSM}$ & $76.1( \pm 0.2)$ & $645( \pm 2)$ & $2.9( \pm 0.2)$ & $133( \pm 2)$ \\
LSMMO & $71.8( \pm 0.1)$ & $536( \pm 3)$ & $2.7( \pm 0.1)$ & $140( \pm 1)$ \\
\hline
\end{tabular}

Sa: arithmetic mean height; Sz: maximum height; Sku: Kurtosis; Sdr: developed interfacial area ratio; LSM: lanthanum manganite strontiumdoped perovskite without molybdenum oxides; LSMMO: lanthanum manganite strontium-doped perovskite with mixed molybdenum oxides.

The actual area is given by the roughness factor and the geometric area. ${ }^{25}$ The actual areas of the LSM and LSMMO electrodes are $1.3(0.2)$ and $1.4(0.1) \mathrm{cm}^{2}$, respectively, and according to the parameters obtained for Sku, the surfaces of both electrodes have a uniform height distribution. ${ }^{38}$

The morphology of electrodes is shown in Figure 2. In Figure 2a, is shown the irregular surface of a single carbon fabric fiber. It is possible to observe that the particles are irregular and uniformly cover the entire fiber of the support material, both in the LSM electrode, Figure 2b, and in the LSMMO electrode, Figure 2c. The LSMMO electrode was analyzed, by SEM and EDS, in relation to the wear of the samples by fifty cycles of voltammetry, with the electrodes being presented before the cycles, Figures $3 \mathrm{a}-3 \mathrm{e}$, and after the cycles, Figures $3 \mathrm{f}-3 \mathrm{j}$, obtaining a chemical mapping of the involved cations. Figures $3 b-3 f$ reveals that the cations $\mathrm{La}, \mathrm{Mn}, \mathrm{Sr}$, and Mo were successfully dispersed throughout the coating, confirming the efficiency of the synthesis and coating processes and the homogeneity of the electrocatalyst. Despite slight leaching of the materials deposited on the electrodes, Figure $3 \mathrm{f}$, the deposited cations remain supported even after polarization.

\section{Electrode performance}

\section{Electrocatalytic properties}

The electrodes were immersed in $0.40 \mathrm{~mol} \mathrm{~L}^{-1} \mathrm{KOH}$, 

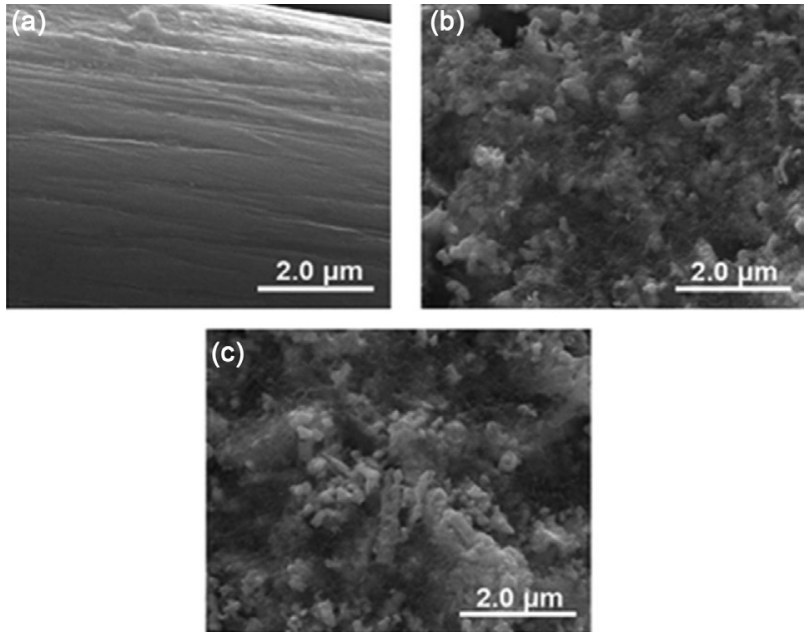

Figure 2. SEM images of the (a) carbon cloth, (b) LSM and (d) LSMMO deposited electrodes.

with and without $0.10 \mathrm{~mol} \mathrm{~L}^{-1} \mathrm{H}_{2} \mathrm{O}_{2}$. Voltammograms recorded at a scan rate of $20 \mathrm{mV} \mathrm{s}^{-1}$, Figure 4a indicates no effective catalytic performance without hydrogen peroxide, but a slight reduction process is observed. The application of a cathodic current can promote a reduction of the interstitial manganese and the perovskite network, promoting oxygen vacancies on the surface of the electrodes containing the strontium-doped lanthanum manganese,${ }^{41}$ which improves the catalytic performance of perovskite. ${ }^{42}$ This phenomenon may be responsible for the behavior of LSM and LSMMO electrodes reduction without hydrogen peroxide. The measurements with $\mathrm{H}_{2} \mathrm{O}_{2}$ show the reduction reaction of hydrogen peroxide in the potential range from $0.00 \mathrm{~V}$ to $-0.85 \mathrm{~V}$. A cathode peak is observed near $-0.6 \mathrm{~V}$ (vs. Ag/ $\mathrm{AgCl}$ ) for both the LSM and the LSMMO electrodes. This peak was already reported in a similar study using platinum as an electrode..$^{43}$ Although this peak was mainly attributed to the hydrogen peroxide reduction reaction (HPRR), it is more accurate to consider the concomitant reactions of hydrogen peroxide reduction and oxygen reduction (ORR). The spontaneous decomposition of hydrogen peroxide, equation 5 , generates oxygen molecules that simultaneously undergo a reduction reaction with the hydrogen peroxide reduction reaction in the electrodes..$^{15,43-45}$ It is very likely that the electroactive species, $\mathrm{HO}_{2}{ }^{-}$and $\mathrm{O}_{2}$, are adsorbed on the surface of the electrodes and are reduced by the HPRR and ORR processes, respectively. ${ }^{12,25,45}$

The voltammograms in Figure 4a show the influence of molybdenum on HPRR catalysis. Near $-0.6 \mathrm{~V}$, the cathodic current density of LSMMO ( $\left.45 \mathrm{~mA} \mathrm{~cm}^{-2}\right)$ is $32 \%$ higher than the current density of LSM $\left(34 \mathrm{~mA} \mathrm{~cm}^{-2}\right)$. Figure $4 \mathrm{a}$ also reveals that the support, the carbon cloth or fiber, does not significantly interfere in the electrochemical process.

The mixed molybdenum oxides, LaMo and SrMo, without the presence of perovskite, were evaluated with and without hydrogen peroxide, Figure $4 b$, to assess the effect of these oxides on the performance in the electrodes. In Figure $4 \mathrm{~b}$, it is possible to observe that the electrodes do not present interference without hydrogen peroxide. However, in both materials, LaMo and SrMo, in the presence of hydrogen peroxide, a response in the reduction reaction is observed, between -0.2 and $-0.4 \mathrm{~V}$, indicating an effect of these oxides in the reduction reactions, mainly for ORR. ${ }^{45}$

Individually, none of these oxides in LaMo and SrMo outperform perovskite, as shown by the LSM electrode Figure 4a, which indicates that $\mathrm{Mn}^{3+}$ and $\mathrm{Mn}^{4+}$ species are present in the cathode materials LSM and LSMMO is the main responsible for the occurrence of HPRR. ${ }^{16}$ Nevertheless, the synergy between these oxides and perovskite can promote better electrochemical performance. The LSMMO electrode improved kinetic and catalytic activities for $\mathrm{H}_{2} \mathrm{O}_{2}$ reduction in the alkaline medium. The presence of mixed molybdenum oxides may
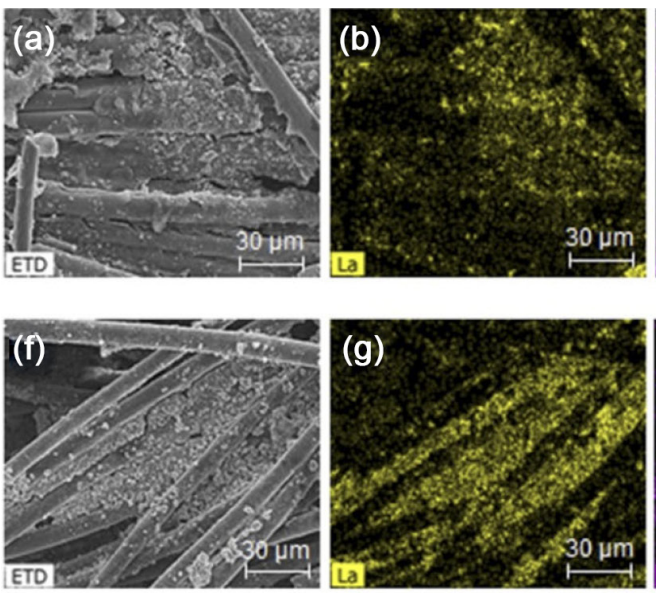
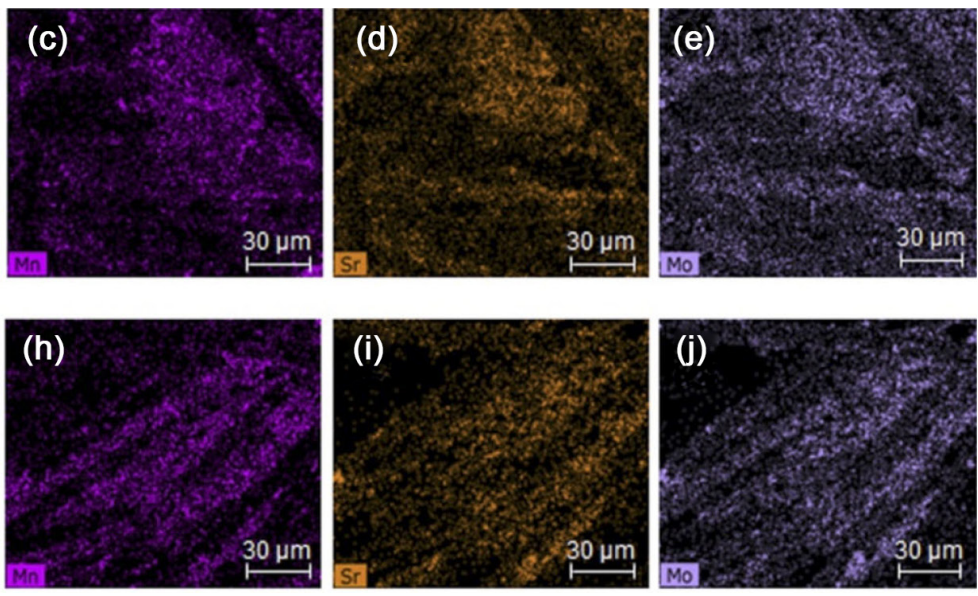

Figure 3. SEM image of the LSMMO electrode before polarization (a) and the respective chemical maps (b-e). SEM image of the LSMMO electrode after polarization (f) and chemical maps ( $\mathrm{g}-\mathrm{j})$. 

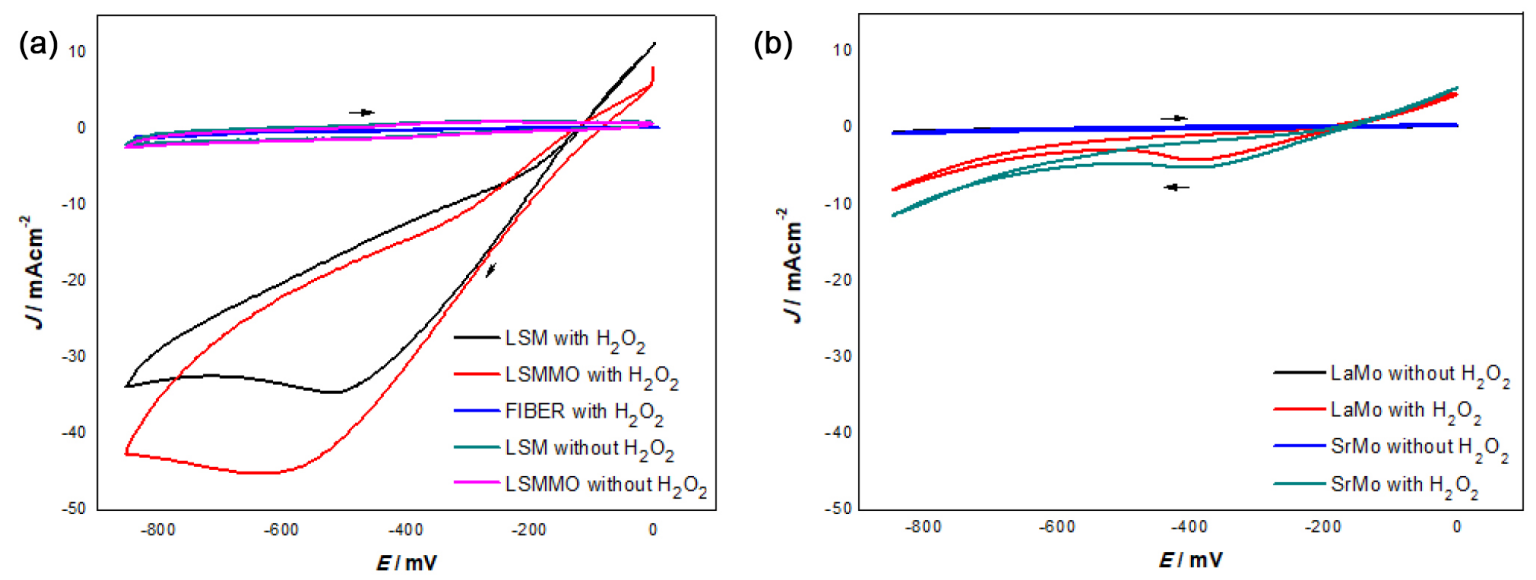

Figure 4. Cyclic voltammograms of (a) LSM and LSMMO without $\mathrm{H}_{2} \mathrm{O}_{2}$, carbon cloth electrodes, LSM and LSMMO with $\mathrm{H}_{2} \mathrm{O}_{2}$, (b) $\mathrm{LaMo}$ and $\mathrm{SrMo}$ without $\mathrm{H}_{2} \mathrm{O}_{2}$, LaMo and SrMo witht $\mathrm{H}_{2} \mathrm{O}_{2}$, measured at $0.40 \mathrm{~mol} \mathrm{~L}^{-1} \mathrm{KOH}$ solution and $0.10 \mathrm{~mol} \mathrm{~L}^{-1} \mathrm{H}_{2} \mathrm{O}_{2}$ solution. A scan rate of $20 \mathrm{mV} \mathrm{s}{ }^{-1}$ and potential / V vs. $\mathrm{Ag} / \mathrm{AgCl} /$ saturated $\mathrm{KCl}$.

be too responsible for better conductivity of the electrode and, consequently, an improvement in the catalytic performance. ${ }^{22,25}$ The values found for the current density in this research are close to those reported in the literature for oxides of the LSM. ${ }^{27}$

\section{Scan-rate effect for electrocatalytic activity}

The applied scan rate influences the behavior observed in cyclic voltammetry tests. Figures $5 a-5 b$ show the electrocatalytic behavior of the LSMMO and LSM electrodes by varying the scan-rate. The observed CV curves indicate the occurrence of an irreversible system. ${ }^{44,46}$ As shown in Figures $5 a-5 b$, when the scan rate was increased, the cathodic peak current density also increased after a slight variation in potential.

The linear relationship between the cathode peak current density $\left(I_{c}\right)$ and the square of the sweep rate $\left(v^{1 / 2}\right)$ (Figures 5c-5d) indicates a diffusion-controlled process of the hydrogen peroxide electro-reduction reaction in the LSMMO catalyst. ${ }^{47-49}$ Besides, it is possible to observe in Figures $5 \mathrm{a}-5 \mathrm{~b}$ a displacement of the reduction potential with the scanning speed indicating a kinetic limitation to the HPRR. ${ }^{50}$ This linear relationship, thus, confirms that the reduction of the hydrogen peroxide electrode in LSMMO is an irreversible process. Based on the observations above, the cathodic peak current $\left(\mathrm{I}_{\mathrm{pc}}\right)$ can be described by the equation below (equation 9). ${ }^{49}$

$$
\mathrm{I}_{\mathrm{pc}}=-2,99 \times 10^{5} \mathrm{nAC}\left(\alpha \mathrm{n}^{\prime}\right)^{0.5} \mathrm{D}^{0.5} \mathrm{v}^{0.5}
$$

where $\mathrm{n}$ represents the number of transferred electrons during the hydrogen peroxide reduction reaction $(n=2)$, A represents the electroactive area of the working electrode, $\mathrm{C}$ is the hydrogen peroxide concentration $\left(\mathrm{C}=0.10 \mathrm{~mol} \mathrm{~L}^{-1}\right), \mathrm{n}$ ' is the number of electrons transferred in a control rate step (n' $=1$ ), D is the diffusion coefficient $\left(\mathrm{D}=0.83 \times 10^{-5} \mathrm{~cm}^{2} \mathrm{~s}^{-1}\right)$ and $\alpha$ is the irreversible reaction parameter $(\alpha=0.45)$ (Figure S3, Table S2, SI section). ${ }^{15,50}$

For non-metallic electrodes with irregular surfaces, in many cases, the electroactive area, where electrochemical reactions occur, is significantly different from the geometric area. ${ }^{51,52}$ Thus, to better understand the electrochemical responses presented, the electroactive area of the LSMMO and LSM electrodes was determined using equation 9.

The values found for the electroactive areas were 2.3 and $1.6 \mathrm{~cm}^{2}$ for the LSMMO and LSM electrodes, respectively. The found values show a higher electroactive area for the LSMMO electrode compared to the LSM electrode. A larger electroactive area for LSMMO was expected from the electrochemical results. It may have occurred due to the presence of molybdenum oxides mixed with strontium and lanthanum by synergy with perovskite. They can promote better electrochemical performance, promoting a larger electrically active area. ${ }^{22,25}$

\section{Effect of $\mathrm{H}_{2} \mathrm{O}_{2}$ concentration on HPRR on LSMMO electrode}

Figure 6 a shows the influence of the hydrogen peroxide concentration on the electrocatalytic activity of the LSMMO catalyst supported on carbon tissue. The $\mathrm{KOH}$ concentration was fixed at $0.40 \mathrm{~mol} \mathrm{~L}^{-1}$. In comparison, the peroxide concentration was changed from 0.07 to $0.10 \mathrm{~mol} \mathrm{~L}^{-1}$. It can be seen that the catalytic performance is strongly dependent on the peroxide concentration and the current density increases linearly with increasing hydrogen peroxide concentration, as shown in Figure 6b. This suggests that LSMMO is suited for the study on HPRR. ${ }^{53,54}$ Slope changes of the voltammetry curve between -0.5 and $-0.6 \mathrm{~V}$ are observed for the HPRR ${ }^{54} \mathrm{In}$ all concentrations, there is a limitation of increasing the cathodic current density. This is probably caused by the 

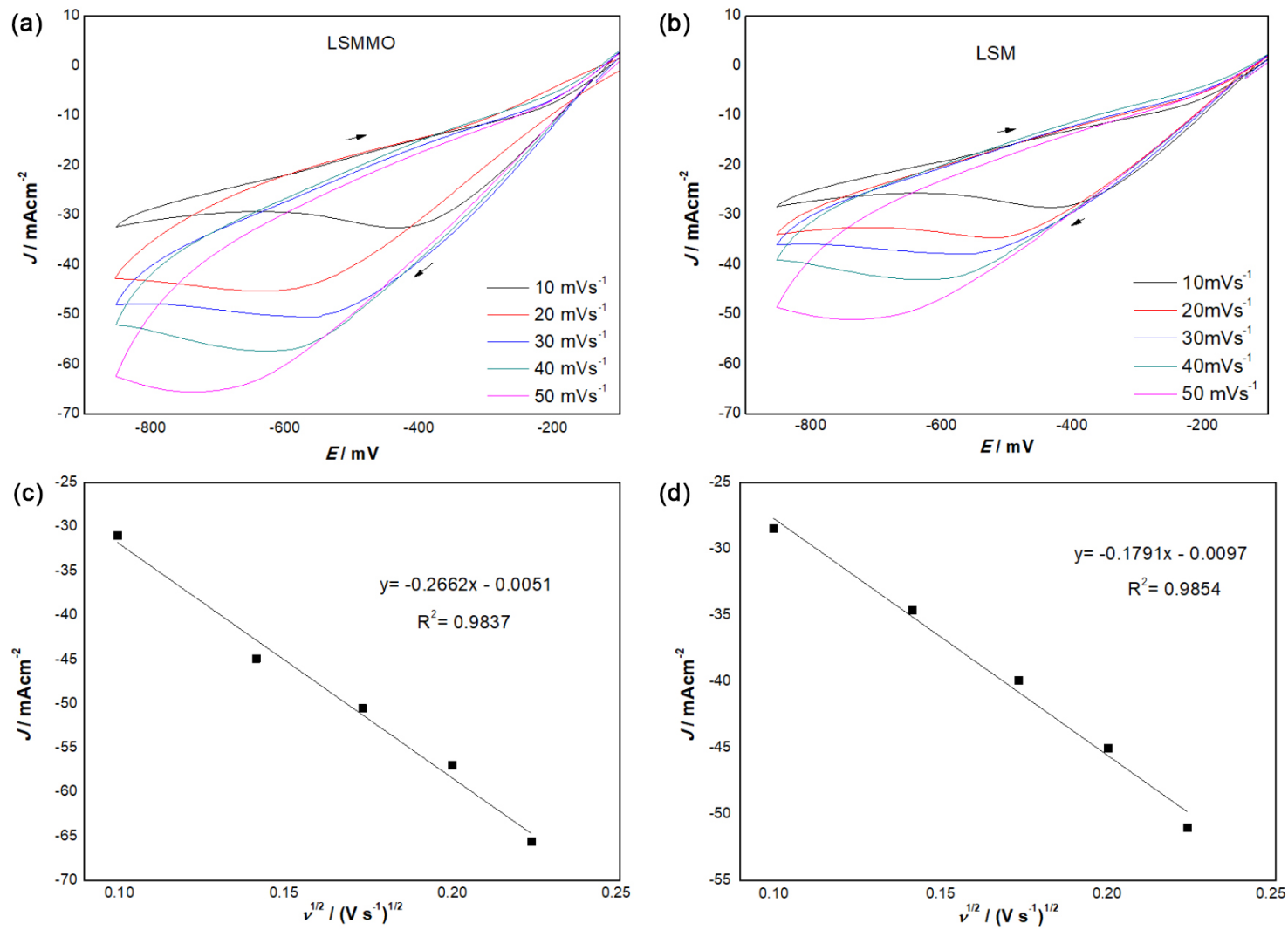

Figure 5. Cyclic voltammograms at different scan rates of the LSMMO (a) and LSM (b) electrode measured in $0.10 \mathrm{~mol} \mathrm{~L}^{-1} \mathrm{H}_{2} \mathrm{O}_{2}$ with $0.40 \mathrm{~mol} \mathrm{~L}{ }^{-1} \mathrm{KOH}$ solution, the relationship between cathodic peak current density and the square root of scan rate of the LSMMO (c) and LSM (d) electrode. Potential / V vs. $\mathrm{Ag} / \mathrm{AgCl} / \mathrm{saturated} \mathrm{KCl}$.

limitation of mass transport, which can be minimized by using the electrolyte flow.

\section{Single compartment cell performance test}

The materials were subjected to electrochemical impedance spectroscopy (EIS) analysis in a single compartment system (Figure S4, SI section) fuel cell, in which hydrogen peroxide, in an alkaline medium, behaved both as a fuel and an oxidizer. This characterization

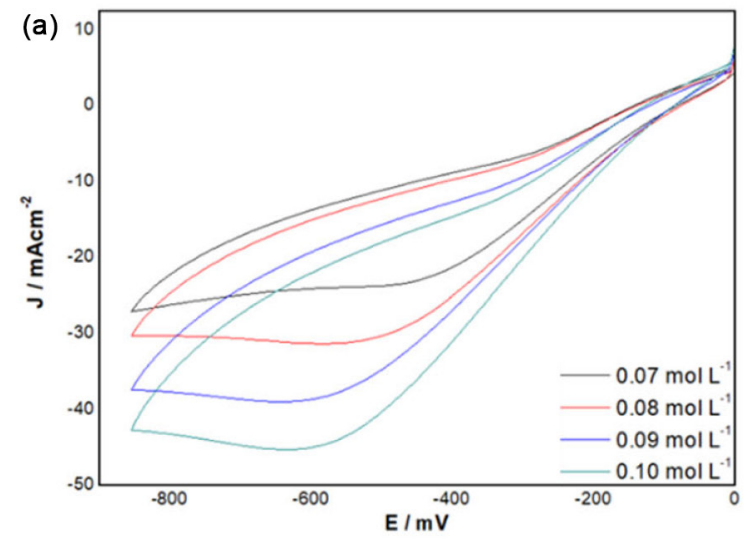

was carried out to study the effect of applying a cathodic current and the presence of mixed molybdenum oxides on the electrochemical behavior of the system. Lanthanum manganites are electron conductors, ${ }^{41}$ and mixed molybdenum oxides influence the electrical conductivity of materials..$^{55} \mathrm{~A}$ metal nickel plate with an area of $1.00 \mathrm{~cm}^{2}$ was used as the anode, and LSM and LSMMO electrodes supported in carbon cloth were the cathodes. The electrolyte consisted of $0.10 \mathrm{~mol} \mathrm{~L}^{-1} \mathrm{H}_{2} \mathrm{O}_{2}$

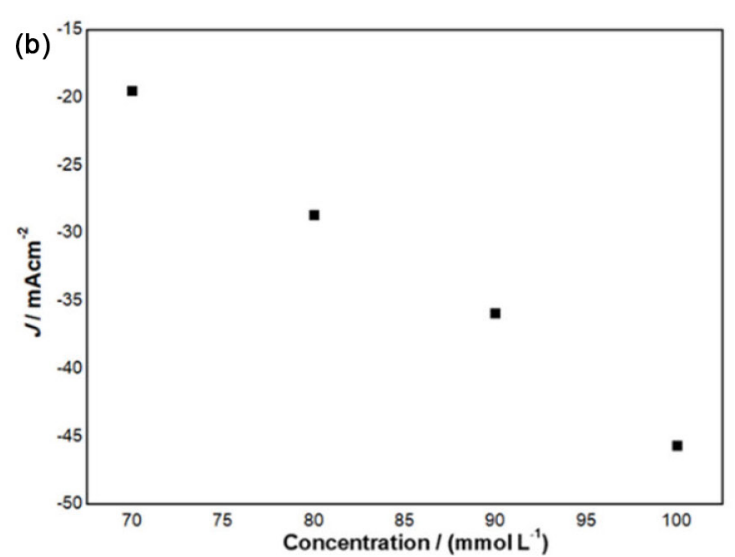

Figure 6. (a) Cyclic voltammograms of the LSMMO and (b) peak current density as a function of $\mathrm{H}_{2} \mathrm{O}_{2}$ concentrations in $0.40 \mathrm{~mol} \mathrm{\textrm {L } ^ { - 1 }} \mathrm{KOH}$; scan rate: $20 \mathrm{mV} \mathrm{s}^{-1}$ and potential $\mathrm{Ag} / \mathrm{AgCl} /$ saturated $\mathrm{KCl}$. 
and $0.40 \mathrm{~mol} \mathrm{~L}^{-1}$ before and after polarization at $-0.85 \mathrm{~V}$ for $300 \mathrm{~s}$. The electrolyte consisted of $0.10 \mathrm{~mol} \mathrm{~L}^{-1} \mathrm{H}_{2} \mathrm{O}_{2}$ and $0.40 \mathrm{~mol} \mathrm{~L}^{-1} \mathrm{KOH}$.

Electrochemical impedance diagrams of conductive materials, being electronic and ionic conductors, can be interpreted as the sum of the electrolyte resistance, the impedance associated with the transfer of electrons and ions, given by the phenomena that occur at the interfaces of the collectors/electrodes and electrode/electrolytes and the impedance associated with adsorption and diffusion phenomena. ${ }^{41}$ In this part of the work, we want to evaluate the influence of polarization on the charge transfer resistance related to impedance associated with the interfaces. There are contributions from the LSM or LSMMO/electrolyte and $\mathrm{Ni}$ /electrolyte interfaces. Considering that the contributions related to $\mathrm{Ni} /$ electrolyte can be neglected, as they are in a steady-state, the contributions associated with LSM or LSMMO/electrolyte are the majority. In this work, it is not possible to evaluate the intrinsic properties of the electrodes.

The Nyquist diagrams, shown in Figure 7a, have similar behavior for all configurations. At high frequencies, the electrolyte resistance $\left(\mathrm{R}_{\mathrm{ohm}}\right)$ corresponding to the intersection value on the horizontal axis is observed ${ }^{56} \mathrm{At}$ medium frequencies, a semicircle is associated with the charge transfer process, and at low frequencies, a behavior associated with diffusion is observed. ${ }^{56} \mathrm{R}_{\mathrm{ohm}}$ is, as expected, located in the same position for both LSM and LSMMO when using a $0.10 \mathrm{~mol} \mathrm{~L}^{-1} \mathrm{H}_{2} \mathrm{O}_{2}$ solution. The charge transfer resistance $\left(\mathrm{R}_{\mathrm{ct}}\right)$ is determined by simulating an equivalent circuit of a resistance in series with Warburg impedance and parallel with a constant phase element (CPE).

Generally, the electrical double layer at the electrodeelectrolyte interface does not have a pure capacitance behavior and is associated with an impedance called the "constant phase element", CPE, ${ }^{57,58}$ which has a frequency- independent phase angle other than 90. This behavior is mainly associated with the inhomogeneity of the solid electrode that leads to a current density distribution. ${ }^{59-61}$

The mathematical expression of the CPE (equation 10) is:

$\mathrm{Z}_{\mathrm{CPE}}=\frac{1}{\mathrm{~T}(\mathrm{i} \omega)^{\mathrm{P}}}$

where $\mathrm{T}$ and $\mathrm{P}$ are the parameters used in the simulation of CPE. When $\mathrm{P}$ ca. 0.5, the process is purely diffusive and $\mathrm{Z}_{\mathrm{CPE}}$ is a Warburg impedance. When $\mathrm{P}$ ca. 1 , the process is strictly capacitive and $T$ corresponds to the capacitance value.

The CPE element represents a non-ideal capacitor and replaces the capacitance due to its roughness and heterogeneous surface. A typical behavior may happen because of the limitation in mass transport due to the diffusion of ions through rough surface electrodes and homogeneous decomposition reactions, which is expectable in perovskite catalysts. ${ }^{17}$ The calculated values for each element after the simulation of the equivalent circuit of Figure $7 \mathrm{a}$ are represented in Table 2 . $\mathrm{P}<1$ values confirm the inhomogeneity of the electrode surface.

Warburg's impedance is due to the diffusion of ions from the electrolyte to the electrode. ${ }^{58}$ The Warburg element used in the simulation is a generalized finite Warburg element, GFW, of expression $\left(Z V_{i e w}{ }^{\circledR}\right)$ :

$\mathrm{W}_{\mathrm{S}}=\frac{\mathrm{W}_{\mathrm{R}}}{\left(j \mathrm{~W}_{\mathrm{T}} \omega\right)^{\mathrm{W}_{\mathrm{P}}}} \tanh \left(j \mathrm{~W}_{\mathrm{T}} \omega\right)^{\mathrm{W}_{\mathrm{P}}}$

where $\mathrm{W}_{\mathrm{R}}, \mathrm{W}_{\mathrm{T}}$ and $\mathrm{W}_{\mathrm{P}}$ are the parameters used in the simulation of $\mathrm{W}_{\mathrm{S}}, \mathrm{j}$ is the current and $\omega$ is the phase angle.

This element translates a slow or finite diffusion through the electrode and is observed in the semicircle at the lowfrequency end.
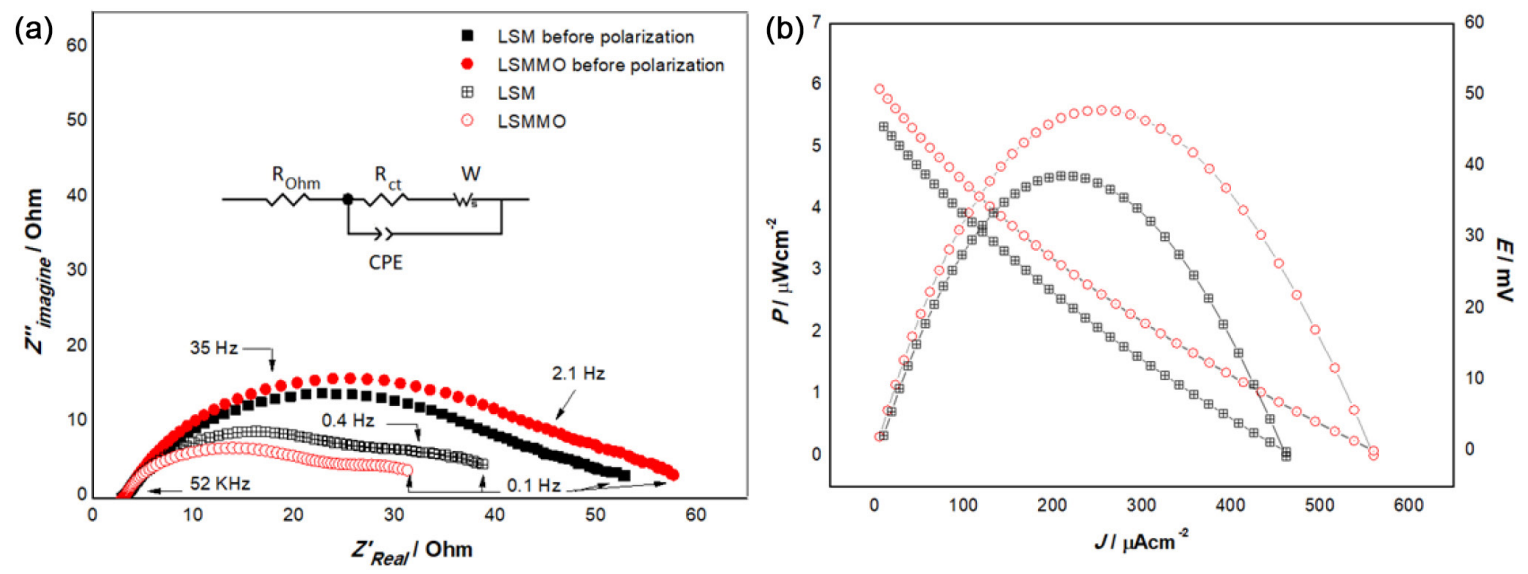

Figure 7. (a) Nyquist plot of single compartment direct hydrogen peroxide stack using a nickel plate as anode catalyst and various cathode catalysts (LSM and LSMMO) and (b) potential and power density of the fuel cell after polarization, operated within $0.10 \mathrm{~mol} \mathrm{~L}^{-1}$ of $\mathrm{H}_{2} \mathrm{O}_{2}$ and $0.40 \mathrm{~mol} \mathrm{~L}-1$ of KOH. At the top of the Nyquist diagram is the equivalent circuit of the system. 
Table 2. EIS parameters for the fuel cell of single compartment direct hydrogen peroxide using nickel plate as the anode catalyst and LSM and LSMMO cathode catalysts, operated with $0.40 \mathrm{~mol} \mathrm{~L}^{-1} \mathrm{KOH}$ and $0.1 \mathrm{~mol} \mathrm{~L}^{-1} \mathrm{H}_{2} \mathrm{O}_{2}$ solutions

\begin{tabular}{|c|c|c|c|c|c|c|c|}
\hline \multirow[b]{2}{*}{ Anode-cathode catalyst } & \multirow{2}{*}{$\begin{array}{c}\mathrm{R}_{\mathrm{ohm}} / \\
\left.(\mathrm{ohm} \mathrm{cm})^{2}\right)\end{array}$} & \multirow{2}{*}{$\begin{array}{c}\mathrm{R}_{\mathrm{ct}} / \\
\left(\mathrm{ohm} \mathrm{cm} \mathrm{cm}^{2}\right)\end{array}$} & \multicolumn{2}{|c|}{$\mathrm{CPE} /\left(\mathrm{F} \mathrm{cm}^{-2} \mathrm{~s}^{-\mathrm{n}}\right)$} & \multicolumn{3}{|c|}{ GFW } \\
\hline & & & $\begin{array}{c}\mathrm{T} \times 10^{-3} / \\
\left(\mathrm{s}^{\mathrm{n}} \mathrm{ohm}^{-1} \mathrm{~cm}^{-2}\right)\end{array}$ & $\mathrm{P}$ & $\begin{array}{c}\mathrm{W}_{\mathrm{R}} / \\
\text { (ohm cm²) }\end{array}$ & $\mathrm{W}_{\mathrm{T}} / \mathrm{s}^{-1}$ & $\mathrm{~W}_{\mathrm{P}}$ \\
\hline Ni-LSM & 3.50 & 24.12 & 1.38 & 0.76 & 14.03 & 1.50 & 0.41 \\
\hline Ni-LSMMO & 3.48 & 16.38 & 1.22 & 0.78 & 16.20 & 2.90 & 0.31 \\
\hline Ni-LSM before polarization & 3.51 & 42.03 & 0.72 & 0.74 & 6.65 & 0.85 & 0.51 \\
\hline Ni-LSMMO before polarization & 3.49 & 45.89 & 0.56 & 0.76 & 9.16 & 0.83 & 0.47 \\
\hline
\end{tabular}

$\mathrm{R}_{\mathrm{ohm}}$ : ohmic resistance; $\mathrm{R}_{\mathrm{c}}$ : charge transfer resistance; CPE: constant phase element defined by two values, $\mathrm{T}$ and P; GFW: generalized Finite Warburg element defined by three values, $\mathrm{W}_{\mathrm{R}}, \mathrm{W}_{\mathrm{T}}$ and $\mathrm{W}_{\mathrm{P}}$; LSM: lanthanum manganite strontium-doped perovskite without molybdenum oxides; LSMMO: lanthanum manganite strontium-doped perovskite with mixed molybdenum oxides.

For total resistance, Figure 7a, when observing the behavior of non-polarized electrodes, the LSMMO electrode presents a resistance superior to the LSM, which was already expected, probably due to the presence of $\mathrm{SrMo}_{4}$ oxide, which could increase the material resistance. ${ }^{55}$ For both electrodes, a considerable decrease in the charge transfer resistance after polarization is observed. This result agrees with what was previously reported, where the application of cathodic currents promotes an increase in active sites on the perovskite surface due to the interstitial reduction of manganese. ${ }^{41}$ After polarization, there is a slight improvement in the LSMMO electrode compared to LSM, which suggests that the polarization may have influenced the oxidation state of part of the mixed molybdenum oxides, as $\mathrm{SrMoO}_{4}$ can be easily reduced to $\mathrm{SrMoO}_{3},{ }^{56}$ which is a better conductor. ${ }^{55}$

Both HPRR and ORR reactions occur at the cathode due to hydrogen peroxide decomposition. The data in Figure $7 \mathrm{~b}$ shows that the LSMMO based cell presented a power density of $5.6 \mu \mathrm{W} \mathrm{cm} \mathrm{cm}^{-2}$ which is $21 \%$ higher than the value of LSM $\left(4.6 \mu \mathrm{W} \mathrm{cm}{ }^{-2}\right)$. The results showed a significant influence on the resistance of the system. During the evolution of the potential as a function of the current density, the ohmic drop is mainly observed related to the electrical resistance of the materials that make up the fuel cell. We effectively observe a linear decrease of the potential. ${ }^{62}$ The drops related to electrode activation at low current densities and reagent diffusion are not clearly observed at high current densities. Yang et al. ${ }^{58}$ reported power density values higher than those described in this work, with $\mathrm{pH}$ variation for direct peroxide-peroxide fuel cell in different compartments. This variation is explained by the fact that this work measures the performance of cathodic catalysts and, for that purpose, adopted an assembly in a single compartment, at the same $\mathrm{pH}$, which reduces the potential difference of the battery and, consequently, its power density.

After polarization, the calculated impedances agree with the fuel cell power density behavior: LSMMO has the lowest total resistance value, higher conductivity, and higher power density than LSM.

The values found for cell performance are lower than those described for DLFCs. ${ }^{19}$ This can be attributed to the very different configuration; the system was built without flow and presented a small potential difference that indicates that nickel is not the ideal anode for this stack. Although nickel is a material widely used in electrochemical catalysts, ${ }^{63}$ the nickel electrode has a small active area, a morphology with a larger area would probably favor the performance of the fuel cell. Despite the influence of the cell assembly, the experiments carried out were sufficient to show that mixed molybdenum oxides influence the performance of a DLFC cell and that the HPRR is catalyzed by LSM perovskite.

\section{Conclusions}

The LSM and LSMMO electrodes, supported on carbon cloth, were produced by the sol-gel route, with citric acid as a precursor, for application in the hydrogen peroxide reduction reaction.

In an alkaline medium in which hydrogen peroxide acted both as fuel and oxidant, the LSMMO catalyst presented higher current densities and more than twice the power densities than LSM in a single compartment cell. The coexistence of $\mathrm{Mn}^{3+}$ and $\mathrm{Mn}^{4+}$ species in both cathode materials allowed HPRR to occur. It has been observed that activation losses due to cell assembly limit the electrochemical performance.

The synergy of mixed perovskite and molybdenum oxides, after polarization, promoted better catalytic properties than LSM perovskites. The presence of molybdenum cations in the strontium-doped lanthanum manganite electrode significantly improved the catalytic activity of the hydrogen peroxide and oxygen reduction reactions. 


\section{Supplementary Information}

Supplementary information is available free of charge at http://jbcs.sbq.org.br as PDF file.

\section{Acknowledgments}

The authors thank the LAMPAC team, UFMG microscopy center and the Chemistry Department of UFMG. Special thanks are also addressed to Prof Wagner da Nova Mussel for the precious insight on crystallographic structure representations.

This study was financed in part by the Coordenação de Aperfeiçoamento de Pessoal de Nível Superior - Brasil (CAPES) - Finance Code 001, CNPQ, FAPEMIG (CEX PPM-00367-17) (Public Organization).

\section{Author Contributions}

Ludmila Oliveira was responsible for conceptualization, data curation, investigation, validation, writing original draft, writing-review and editing; Therese Cibaka for writing original draft, writing-review and editing; Renata Diniz for writing original draft, writing-review and editing; Vanessa F. C. Lins for writing original draft, visualization, writing-review and editing; Luciano Montoro for conceptualization, resources, visualization, writing-review and editing; Tulio Matencio for conceptualization, formal analysis funding acquisition, project administration, resources, visualization, writing original draft, writing-review and editing.

\section{References}

1. Chu, S.; Majumdar, A.; Nature 2012, 488, 294.

2. Amrouche, A.; Messaoud, F.; Boutarek-Zaourar, N.; David, P.; Mossang, E.; Mansour, S.; Slimane, M.; J. Solid State Electrochem. 2019, 23, 2961.

3. Fukuzumi, S.; Yamada, Y.; ChemElectroChem 2016, 3, 1978.

4. Ong, B. C.; Kamarudin, S. K.; Basri, S.; Int. J. Hydrogen Energy 2017, 42, 10142.

5. Demirci, U. B.; Environ Int. 2009, 35, 626.

6. Kim, M.-S.; Fang, B.; Chaudhari, N. K.; Song, M.; Bae, T.-S.; Yu, J.-S.; Electrochim. Acta 2010, 55, 4543.

7. Yang, Y.; Wang, W.; Liu, Y.; Wang, F.; Zhang, Z.; Lei, Z.; Int. J. Hydrogen Energy 2015, 40, 2225.

8. Han, X.; Chadderdon, D. J.; Qi, J.; Xin, L.; Li, W.; Zhou, W.; Int. J. Hydrogen Energy 2014, 39, 19767.

9. Aslam, N.; Masdar, M.; Kamarudin, S.; Daud, W.; APCBEE Proc. 2012, 3, 33.

10. Sakamoto, T.; Deevanhxay, P.; Asazawa, K.; Tsushima, S.; Hirai, S.; Tanaka, H.; J. Power Sources 2014, 252, 35.

11. Wang, G.; Bao, Y.; Tian, Y.; Xia, J.; Cao, D.; J. Power Sources
2010, 195, 6463.

12. Wang, Y.; Guo, Z.; Xia, Y.; Energy Mater. 2013, 3, 713.

13. Geng, X.; Zhang, H.; Ye, W.; Ma, Y.; Zhong, H.; J. Power Sources 2008, 185, 627.

14. Hasvold, Ø.; Størkersen, N. J.; Forseth, S.; Lian, T.; J. Power Sources 2006, 162, 935.

15. Prater, D. N.; Rusek, J.; Appl. Energy 2003, 74, 135.

16. Yan, X. H.; Zhao, T. S.; An, L.; Zhao, G.; Shi, L.; Int. J. Hydrogen Energy 2016, 41, 5135.

17. Yunphutthaa, C.; Porntheeraphatc, S.; Midpanona, S.; Wongchaisuwat, A.; Viravatana, P.; J. Power Sources 2018, 392, 251.

18. Zhuang, C.; Dongming, Z.; Liangliang, G.; Liu, P.; Ye, K.; Cheng, K.; Cao, D.; Wang, G.; RSC Adv. 2016, 6, 2546.

19. Poux, T.; Bonnefont, A.; Ryabova, A.; Kéranguéven, G.; Tsirlina, G. A.; Savinova, E. R.; Phys. Chem. Chem. Phys. 2014, 16, 13595.

20. Li, X.; Zhou, S.; Wu, Q.; Wang, X.; Yao, T.; Zhang, Z.; Song, B.; Solid State Ionics 2019, 334, 14.

21. Barbucci, A.; Carpanese, P.; Cerisola, G.; Viviane, M.; Solid State Ionics 2005, 176, 1753.

22. Bode, G. L.; McIntyre, M. D.; Neuberger, D. M.; Walker, R. A.; Thorstensen, B. P.; ChemElectroChem 2018, 5, 3162.

23. Bezerra, F. A.; Altino, H. O. N.; Soares, R. R.; J. Braz. Chem. Soc. 2019, 30, 1025 .

24. Medina, M.; Corradini, P. G.; Mascaro, L. H.; J. Braz. Chem. Soc. 2019, 30, 2210.

25. Kindermann, L.; Das, D.; Nickel, H.; Hilpert, K.; Solid State Ionics 1996, 89, 215.

26. Rabelo, A. A.; de Macedo, M. C.; Melo, D. M. D. A.; Paskocimas, C. A.; Martinelle, A. E.; do Nascimento, R. M.; Mater. Res. 2011, 14, 91.

27. Yunphuttha, C.; Porntheeraphat, S.; Wongchaisuwat, A.; Tangbunsuk, S.; Marr, D. W. M.; Viravatana, P.; Phys. Chem. Chem. Phys. 2016, 18, 16786.

28. Eriksson, S. G.; Ivanov, S.; Eriksen, J.; Valkeapää, M.; Johansson, L. G.; Rundlöf, H.; McGreevy, R.; Berastequi, P.; Björnsson, P.; Rubhausen, M.; Bäckström, J.; Käll, M.; Börjesson, L.; Mater. Sci. Forum 2001, 381, 505.

29. Bommer, H.; Zeitschrift für anorganische und allgemeine Chemie 1939, 241, 273.

30. Tismenko, Y. K. E.; Simonov, M. A.; Belov, N. V.; Kristallografiya 1967, $12,511$.

31. Efremov, V. A.; Tyulin, A. V.; Trunov, V. K.; Koord. Khim. 1987, 13, 1276.

32. Rietveld, H.; J. Appl. Crystallogr. 1969, 2, 65.

33. Plonczak, P.; Soerensen, D.; Soegaard, M.; Esposito, V.; Hendriksen, P. V.; Solid State Ionics 2012, 217, 54.

34. Jiankang, L.; Huan, Z.; Zenghe, L.; RSC Adv. 2016, 6, 77786.

35. Li, Y.; Xu, C.; Dang, M.; Yu, C.; He, Y.; Liu, W.; Jin, H.; Li, W.; Zhu, M.; Zhang, J.; Ceram. Int. 2021, 47, 21759. 
36. Fearn, S.; Rossiny, J.; Kilner, J.; Evans, J. R. G.; Solid State Ionics 2012, 211, 51.

37. Jouannaux, J.; Haeusslerb, A.; Drobeka, M.; Ayral, A.; Abanades, S.; Ceram. Int. 2019, 45, 15636.

38. Tosello, G.; Micromachines 2019, 10, 340.

39. Zhao, J.-J.; Duan, Y.-Y.; Wang, X.-D.; Wang, B.-X.; J. Heat Transfer 2013, 135, 41502.

40. Leroy, F.; Müller-Plathe, F.; Langmuir 2011, 27, 637.

41. Belardi, R. M.; Deseure, J.; Brand, M. C.; Matencio, T.; Domingues, R. Z.; Ionics (Kiel) 2008, 15, 227.

42. de Souza, S.; Visco, S. J.; Jongue, L. C.; Solid State Ionics 1997, 98, 57.

43. Rormark, L.; Wiik, K.; Stølen, S.; Grande, T.; J. Mater Chem. 2002, 12, 1058.

44. Tulloch, J.; Donne, S. W.; J. Power Sources 2009, 188, 359.

45. Sun, W.; Hsu, A.; Chen, J.; J. Power Sources 2011, 196, 627.

46. Ren, T.; Zhang, J.; Wang, D.; Dong, P.; Duan, J.; Li, X.; Rao, S.; Huang, D.; Zhang, Y.; Ceram. Int. 2018, 44, 14660.

47. Stefanova, V.; Dobrovolska, T. S.; Miletiev, R.; Bulg. Chem. Commun. 2013, 45, 151.

48. Wang, G.; Ye, K.; Shao, J.; Zhang, Z.; Zhu, K.; Cheng, K.; Yan, J.; Wang, G.; Cao, D.; Int. J. Hydrogen Energy 2018, 43, 9316.

49. Barakat, N. A. M.; El-Newehy, M. H.; Yasin, A. S.; Ghouri, Z. K.; Al-Deyab, S. S.; Appl. Catal., A 2016, 510, 180.

50. Hitmi, H.; Belgsir, E. M.; Léger, J. M.; Lamy, C.; Lezna, R. O.; Electrochim. Acta 1994, 39, 4686.
51. Trasatti, S.; Petrii, O. A.; Pure Appl. Chem. 1991, 63, 711.

52. Takeda, K.; Kusuoka, R.; Birrell, J. A.; Yoshida, M.; Igarashi, K.; Nakamura, N.; Electrochim. Acta 2020, 359, 136982.

53. Hall, B.; Khudaish, A.; Hart, A.; Electrochim. Acta 1999, 44, 2455.

54. Patra, S.; Munichandraiah, N.; J. Chem. Sci. 2009, 121, 675.

55. Vasala, S.; Yamauchi, H.; Karppinen, M.; J. Solid State Chem. 2011, 184, 1312.

56. Horsley, J. R.; Yu, J.; Wegener, K. L.; Hoppmann, C.; RückBraun, K.; Abell, A. D.; Biosens. Bioelectron. 2018, 118, 188.

57. Heli, H.; Pishahang, J.; Electrochim. Acta 2014, 123, 518.

58. Yang, F.; Cheng, K.; Liu, X.; J. Power Sources 2012, 217, 569.

59. Fricke, H.; Philos. Mag. 1932, 14, 310.

60. Burg, G. J.; Vandeneeden, A. L. G.; Sluytersrehbach, M.; J. Electroanal. Chem. Interfacial Electrochem. 1984, 176, 275.

61. Barsoukov, E.; Macdonald, J. R.; Impedance Spectroscopy Theory, Experiment, and Applications, $2^{\text {nd }}$ ed.; John Wiley \& Sons Inc.: Hoboken, NJ, 2005.

62. Ticianelli, E. A.; Gonzalez, E. R.; Eletroquímica Princípios e Aplicações, 2n ${ }^{\text {nd }}$ ed.; EDUSP: São Paulo, Brazil, 2013.

63. Slis, A.; Mikolajczyk, T.; Pierozynski, B.; J. Braz. Chem. Soc. 2019, 30, 305.

Submitted: November 18, 2021

Published online: January 19, 2022 